\title{
Active surveillance in poultry in Poland for avian influenza subtypes H5 and $\mathrm{H7}$
}

\author{
Anna Pikuła ${ }^{\bowtie}$, Krzysztof Śmietanka, Anna Lisowska and Zenon Minta \\ Department of Poultry Diseases, National Veterinary Research Institute, Puławy, Poland
}

\begin{abstract}
A serological surveillance programme for avian influenza $A$ virus (AIV) subtype $\mathrm{H} 5$ and $\mathrm{H} 7$ in poultry was implemented in Poland in 2008-2013 with two main objectives: i) to detect subclinical infections or previous exposures to AIV $\mathrm{H} 5$ and $\mathrm{H} 7$ subtypes and ii) to demonstrate the Al- free status of Poland. During this period, over 45000 serum samples from 2833 holdings were examined using the hemagglutination inhibition test $(\mathrm{HI})$. The presence of $\mathrm{HI}$ antibodies was detected in 8 breeder geese holdings ( 7 positive for $\mathrm{H} 5$ and 1 positive for $\mathrm{H} 7 \mathrm{AIV}$ ) and in 1 breeder duck holding (H5-positive), which represented $0.32 \%$ of all investigated holdings. All seropositive flocks were examined by real time RT-PCR with negative results, which substantiated the Al-free status of Poland. Positive results detected in clinically healthy poultry kept in an open range system indicate prior infections with low pathogenic AIV originating from the wild-bird reservoir.
\end{abstract}

Key words: avian influenza virus (AIV), poultry, surveillance, hemagglutination inhibition test $(\mathrm{HI})$

Received: 28 May, 2014; revised: 12 August, 2014; accepted: 15 August, 2014; available on-line: 04 September, 2014

\section{INTRODUCTION}

Avian influenza viruses have been isolated from more than 100 different species of wild birds, mostly belonging to the orders: Anseriformes and Charadriiformes (Olsen et al., 2006). Transmission of AIV from wild birds to poultry is a relatively frequent event, but viruses cause none or only mild symptoms and such infections are referred to as low pathogenic avian influenza. Two out of sixteen subtypes of AIV (namely $\mathrm{H} 5$ and H7) have the potential to mutate to a highly pathogenic avian influenza virus. Therefore, the control of AI in poultry is focused on AIV infections by any of the $\mathrm{H} 5$ or $\mathrm{H} 7$ subtypes, regardless of the virulence. The purpose of the surveillance programme implemented in the European Union is to detect subclinical or prior infections in poultry caused by AI subtypes $\mathrm{H} 5$ and $\mathrm{H} 7$ and to demonstrate the disease free status of the country (EC, 2005; EC, 2007; EC, 2010). This paper presents results of an active surveillance for AI in poultry in Poland in 2008-2013.

\section{MATERIALS AND METHODS}

Collection of samples from poultry. Blood samples for serological examination were obtained from poultry by veterinary inspection in accordance with the Commission Decision 2007/268/EC (EC, 2007) and Commission Decision 2010/367/EU (EC, 2010) and approved by the Council of Ministers and European Commission. Samples were collected in 16 Polish provinces from all species of poultry, including different types of production (with the exception of broiler chickens) and farmed game birds. The number of holdings within a province was calculated to ensure detection of at least one infected holding assuming the prevalence of infected holdings was at least 5\%, with a 95\% confidence interval (holdings of chickens, ostriches and game birds) or a $99 \%$ confidence interval (turkey, duck and goose holdings). The number of samples taken from ostrich flocks was 5 , for laying hens, chicken breeders, turkeys and game birds it was 10, and from geese and duck flocks between 20 and 40, to ensure identification of at least one positive bird assuming the prevalence of AIV infection within a flock was about $30 \%$ with a $95 \%$ confidence interval. The larger sample size in the case of geese and ducks was dictated by lower sensitivity of the diagnostic test when used for samples collected from waterfowl (EC, 2010).

Hemagglutination inhibition test. Serum samples were examined by HI for antigens representing two AIV subtypes - H5 (H5N3) and H7 (H7N7) (AHVLA, UK). In the case of positive results, an additional test was performed with $\mathrm{H} 5 \mathrm{~N} 1$ or $\mathrm{H} 7 \mathrm{~N} 1$ antigens in order to rule out the neuraminidase cross-reactive antibodies (EC, 2010). The HI assay was carried out using 4 hemagglutinating units of the AIV antigen, according to the OIE Diagnostic Manual (2008). The cut-off titer for seropositivity was $\geq 16\left(\geq 4 \log _{2}\right)$. All seropositive flocks were retested using AI MultiS- Screen Antibody Test (IDEXX, USA) or ID Screen Influenza H5 or H7 Antibody Competition Kits (ID VET, France), according to the manufacturer's protocols. In response to detecting any seropositive flocks, follow-up investigations were carried out, including an epidemiological inquiry, clinical examination and collection of 20 oropharyngeal and 20 cloacal swabs for molecular diagnosis of AI by real time RT-PCR.

e-mail: anna.pikula@piwet.pulawy.pl

Abbreviations: Al, avian influenza; AIV avian influenza virus; EU, European Union; ELISA, enzyme-linked immunosorbent assay; $\mathrm{HI}$, hemagglutination inhibition test; HPAl, highly pathogenic avian influenza; LPAI, low pathogenic avian influenza; RT-PCR, reverse transcription-polymerase chain reaction. 
Molecular methods of AIV identification. Total RNA was extracted from swab samples using RNeasyMini Kit (Qiagen, Germany), according to the manufacturer's protocol with some modifications. Samples were tested by the real time RT-PCR (rRT-PCR) method, with some modification, to detect the matrix (M) gene of influenza A viruses (Spackman et al., 2002).

Table 1. Results of the serological surveillance of avian influenza in poultry in Poland in 2008-2013.

\begin{tabular}{|c|c|c|c|c|}
\hline Year & Poultry categories & Number of tested flocks & Number of tested samples & $\begin{array}{c}\text { Number of seropositive flocks } \\
\text { (subtype) }\end{array}$ \\
\hline \multirow{8}{*}{2008} & Laying hens & 82 & 820 & 0 \\
\hline & Chicken breeders & 66 & 660 & 0 \\
\hline & Turkey & 72 & 720 & 0 \\
\hline & Geese & 84 & 3360 & 0 \\
\hline & Ducks & 8 & 320 & 0 \\
\hline & Farmed game birds & 31 & 310 & 0 \\
\hline & Ratites & 50 & 250 & 0 \\
\hline & Total: & 393 & 6440 & 0 \\
\hline \multirow{8}{*}{2009} & Laying hens & 66 & 660 & 0 \\
\hline & Chicken breeders & 66 & 660 & 0 \\
\hline & Turkey & 62 & 620 & 0 \\
\hline & Geese & 85 & 3400 & $1(\mathrm{H} 5)^{*}$ \\
\hline & Ducks & 11 & 440 & 0 \\
\hline & Farmed game birds & 36 & 360 & 0 \\
\hline & Ratites & 52 & 260 & 0 \\
\hline & Total: & 378 & 6400 & $1(\mathrm{H} 5)^{*}$ \\
\hline \multirow{8}{*}{2010} & Laying hens & 66 & 660 & 0 \\
\hline & Chicken breeders & 67 & 670 & 0 \\
\hline & Turkey & 94 & 940 & 0 \\
\hline & Geese & 85 & 3400 & $2(\mathrm{H} 5)^{*}$ \\
\hline & Ducks & 13 & 520 & 0 \\
\hline & Farmed game birds & 34 & 340 & 0 \\
\hline & Ratites & 50 & 250 & 0 \\
\hline & Total: & 409 & 6780 & $2(\mathrm{H} 5)^{*}$ \\
\hline \multirow{8}{*}{2011} & Laying hens & 60 & 600 & 0 \\
\hline & Chicken breeders & 64 & 640 & 0 \\
\hline & Turkey & 95 & 950 & 0 \\
\hline & Geese & 99 & 3960 & $3(\mathrm{H} 5)^{*}$ \\
\hline & Ducks & 61 & 2440 & $1(\mathrm{H} 5)^{*}$ \\
\hline & Farmed game birds & 34 & 340 & 0 \\
\hline & Ratites & 48 & 240 & 0 \\
\hline & Total: & 461 & 9170 & $4(\mathrm{H} 5)^{*}$ \\
\hline \multirow{9}{*}{2012} & Laying hens & 91 & 910 & 0 \\
\hline & Free range laying hens & 21 & 210 & 0 \\
\hline & Chicken breeders & 59 & 590 & 0 \\
\hline & Turkey & 79 & 790 & 0 \\
\hline & Geese & 170 & 3400 & $1(\mathrm{H} 7)^{*}$ \\
\hline & Ducks & 92 & 1840 & 0 \\
\hline & Farmed game birds & 36 & 360 & 0 \\
\hline & Ratites & 40 & 200 & 0 \\
\hline & Total: & 588 & 8300 & $1(\mathrm{H} 7)^{*}$ \\
\hline
\end{tabular}




\begin{tabular}{|c|c|c|c|c|}
\hline & Laying hens & 80 & 800 & 0 \\
\hline & Free range laying hens & 29 & 290 & 0 \\
\hline & Chicken breeders & 66 & 660 & 0 \\
\hline & Turkey & 64 & 640 & 0 \\
\hline \multirow[t]{5}{*}{2013} & Geese & 185 & 3700 & $1(\mathrm{H} 5)^{*}$ \\
\hline & Ducks & 95 & 1900 & 0 \\
\hline & Farmed game birds & 38 & 380 & 0 \\
\hline & Ratites & 47 & 235 & 0 \\
\hline & Total: & 604 & 8605 & $1(\mathrm{H} 5)^{*}$ \\
\hline Total: & & 2833 & 45695 & $\begin{array}{l}8(\mathrm{H} 5)^{*} \\
1(\mathrm{H} 7)^{*}\end{array}$ \\
\hline
\end{tabular}

$*_{\text {in }}$ retrospective investigation (virology) indicate lack of active AIV infection

\section{RESULTS AND DISCUSSION}

The detailed results of serological examination of poultry in 2008-2013 in Poland are shown in Table 1. During the 6-year period, 45695 samples of serum from 2833 poultry flocks were tested, including 4950 samples from 495 flocks of conventional and free-range laying hens, 3880 samples from 388 flocks of chicken breeders, 4660 samples from 466 flocks of turkeys (breeders and fattening), 28680 samples from 988 flocks of geese and ducks (breeder and fattening), 2090 samples from 209 flocks of farmed game birds (pheasants) and 1,435 samples from 287 flocks of ratites. The H5 subtype antibodies were found in 7 flocks of breeder geese and in 1 flock of breeder ducks. Moreover, antibodies to H7 subtype of AIV were detected in 1 flock of breeder geese. The seropositive flocks represented $0.32 \%$ of all investigated holdings. The detailed description of seropositive flocks is provided in Table 2. All serum samples from seropositive flocks were additionally examined by the ELISA test, and the obtained results confirmed the presence of type-A specific antibodies (IDEXX AI MultiSScreen $\mathrm{Ab}$ ) and antibodies to $\mathrm{H} 5$ or $\mathrm{H} 7$ AIV subtypes (ID VET ELISA Kits).

The major objective of the active serological surveillance in the EU Member States, i.e. testing live, clinically healthy birds, is to inform competent authorities about circulating $\mathrm{H} 5$ and $\mathrm{H} 7$ strains of LPAIV in gallinaceous poultry (i.e. chickens, turkeys, guinea fowls, partridges, pheasants and quails), ratites and domestic waterfowl (i.e. geese and ducks) as well as $\mathrm{H} 5$ and $\mathrm{H} 7 \mathrm{HPAIV}$ in geese and ducks (EC, 2007; EC, 2010). Early detection of LPAIV of subtypes $\mathrm{H} 5$ and $\mathrm{H} 7$ in poultry can expedite the implementation of control measures in order to prevent its mutation into a HPAI virus. Active surveillance for HPAIV in geese and ducks aims at detecting

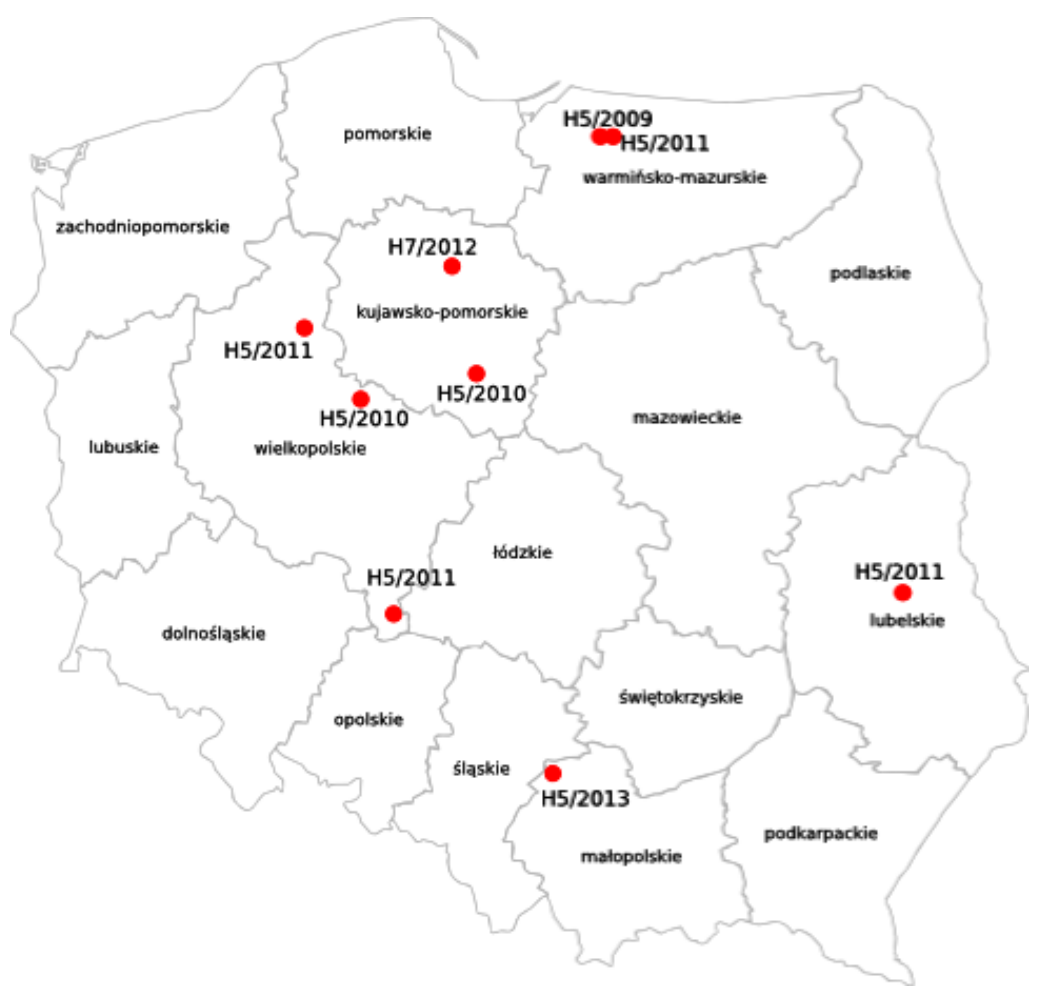

Figure 1. The distribution of seropositive holdings tested during the survey for avian influenza infections in Poland in 2008-2013. 
Table 2. Seropositive poultry flocks.

\begin{tabular}{|c|c|c|c|c|c|c|c|c|}
\hline \multirow{2}{*}{ Year } & \multirow{2}{*}{$\begin{array}{l}\text { Code of } \\
\text { flock }\end{array}$} & \multirow{2}{*}{$\begin{array}{l}\text { Poultry } \\
\text { category }\end{array}$} & \multirow{2}{*}{$\begin{array}{l}\text { Age } \\
\text { (year) }\end{array}$} & \multirow{2}{*}{ AIV subtype } & \multicolumn{3}{|c|}{$\%$ of seropositivity } & \multirow{2}{*}{ Region } \\
\hline & & & & & $\mathrm{HI}$ & $\begin{array}{l}\text { ELISA AI A } \\
(\text { IDEXX) }\end{array}$ & $\begin{array}{l}\text { ELISA H5/H7 } \\
\text { (ID VET) }\end{array}$ & \\
\hline 2009 & M044/09 & breeder geese & 4 & $\mathrm{H} 5$ & $25.0 \%$ & $100.0 \%$ & $52.5 \%$ & Warmińsko-Mazurskie \\
\hline 2010 & M082/10 & breeder geese & 3 & H5 & $50.0 \%$ & $57.5 \%$ & $82.5 \%$ & Wielkopolskie \\
\hline 2010 & $\mathrm{M} 175 / 10$ & breeder geese & 2 & $\mathrm{H} 5$ & $40.0 \%$ & $57.5 \%$ & $100.0 \%$ & Kujawsko-Pomorskie \\
\hline 2011 & M071/11 & breeder ducks & 1 & $\mathrm{H} 5$ & $25.0 \%$ & $100.0 \%$ & $75.0 \%$ & Wielkopolskie \\
\hline 2011 & M182/11 & breeder geese & 4 & $\mathrm{H} 5$ & $27.5 \%$ & $100.0 \%$ & $67.5 \%$ & Warmińsko-Mazurskie \\
\hline 2011 & M334/11 & breeder geese & 3 & $\mathrm{H} 5$ & $42.5 \%$ & $27.5 \%$ & $70.0 \%$ & Wielkopolskie \\
\hline 2011 & M362/11 & breeder geese & 3 & $\mathrm{H} 5$ & $35.0 \%$ & $22.5 \%$ & $65.0 \%$ & Lubelskie \\
\hline 2012 & M232/12 & breeder geese & 4 & $\mathrm{H} 7$ & $40.0 \%$ & $100.0 \%$ & $85.0 \%$ & Kujawsko-Pomorskie \\
\hline 2013 & M149/13 & breeder geese & - & $\mathrm{H} 5$ & $10.0 \%$ & $75.0 \%$ & $60.0 \%$ & Małopolskie \\
\hline
\end{tabular}

subclinical infections since domestic waterfowl, mostly ducks, exhibit a range of clinical outcomes, including asymptomatic infections (Pantin-Jackwood \& Swayne, 2007; Phuong do et al., 2011).

The serosurvey conducted in Poland has indicated a lack of active infections with avian influenza viruses in the poultry population and a low percentage of seropositive holdings $(0.32 \%)$. There were no virus positive results in industrial poultry farms. All positive flocks were waterfowl, mostly breeder geese aged 1-4 years (median age 3 years), kept in an open-range system at least in some periods of their life and which might have had, at least temporarily, a close contact with wild birds representing the potential source of infection (Olsen et al., 2006). Epidemiological investigation in seropositive flocks did not reveal any health disorders, including breeding problems, during the entire lifespan. Our results suggest that seropositive birds were exposed to infection with low pathogenic AIV of wild-bird origin rather than a highly pathogenic AI virus (mostly H5N1 HPAIV) for two reasons. Firstly, an open-range system, in which domestic waterfowl are kept, favours frequent opportunities of direct and indirect contacts with wild birds and the circulation of both $\mathrm{H} 5$ and H7 LPAIV in the wild reservoir has been confirmed in recent years during active surveillance studies carried out in Poland (Smietanka et al., 2011; Smietanka et al., 2012). Moreover, the majority of seropositive holdings were located in regions abundant with lakes, such as the Masurian Lake District, the Great Poland Lakeland and the Lęczna-Włodawa Lakeland (Fig. 1), in which wild waterfowl form massive aggregations in certain seasons. Secondly, although the HI test does not allow for the identification of the neuraminidase subtype, the detailed analysis of all positive results revealed lower titers of antibodies against the secondary $\mathrm{H} 5 \mathrm{~N} 1$ antigen than the primary H5N3 antigen (data not shown).

The results of the surveillance in Poland are similar to those obtained for the whole EU (annual reports published at http://ec.europa.eu/food/animal/diseases/con- trolmeasures/avian/eu_resp_surveillance_en.htm). The slightly higher detection rate noted in Poland $(0.32 \%)$ in comparison to the EU as a whole $(0.21 \%)$ was most likely related to the higher proportion of examined geese and duck holdings (high-risk species), which constituted $34.9 \%$ of the total sampled poultry holdings in Poland. Likewise as in Poland, the highest apparent prevalence for H5 was observed in ducks and geese in other Member States. Seroreagents to H7 subtype were found in Europe mainly in backyard flocks and conventional as well as free-range laying hens.

To summarize, results of the conducted studies indicate that infections with identifiable AI of $\mathrm{H} 5$ and $\mathrm{H} 7$ subtypes in the poultry population in Poland are sporadic and most probably result from the incursions of avian influenza viruses of wild-bird origin.

\section{Acknowledgements}

The authors wish to thank the staff involved in the implementation of the survey, particularly Agata Sieczkowska, Stanisława Sagała, Anna Sawicka and Olimpia Kursa from the Department of Poultry Diseases, NVRI, and Veterinary Inspectors who organized sample collection.

This project was partially supported by the European Commission EU and the Polish Government.

\section{REFERENCES}

EC (2005) Council Directive 2005/94/EC of 20 December 2005 on Community measures for the control of avian influenza and repealing Directive 92/40/EEC, Official Journal of the Eurpean Union, L 237, 31.08.2006. 1-64.

EC (2007) Commission Decision 2007/268/EC of 13 April 2007 on the implementation of surveillance programmes for avian influenza in poultry and wild birds to be carried out in the Member States and amending Decision 2004/450/EC, Official Journal of the European Union L115, 3.5.2007, 1-17.

EC (2010) Commission Decision 2010/367/EU of 25 June 2010 on the implementation by Member States of surveillance programmes 
for avian influenza in poultry and wild birds, Official Journal of the European Union, L 166, 1.7.2010, 1-11.

OIE (World Organisation for Animal Health) (2008) Avian influenza. In: Manual of Diagnostic Tests and Vaccines for Terrestrial Animals. 6th edn, pp 436-454.

Olsen B, Munster VJ, Wallensten A, Waldenstrom J, Osterhaus AD, Fouchier RA (2006) Global patterns of influenza a virus in wild birds. Science 312: 384-388.

Pantin-Jackwood MJ, Swayne DE (2007) Pathobiology of Asian highly pathogenic avian influenza H5N1 virus infections in ducks. Avian Dis 51: 250-259.

Phuong do Q, Dung NT, Jorgensen PH, Handberg KJ, Vinh NT, Christensen JP (2011) Susceptibility of Muscovy (Cairina Moschata) and mallard ducks (Anas Platyrbynchos) to experimental infections by different genotypes of $\mathrm{H} 5 \mathrm{~N} 1$ avian influenza viruses. Vet Microbiol, 148: $168-174$.
Smietanka K, Pikuła A, Minta Z, Meissner W (2011) Evidence of persistence and multiple genetic modifications of H7N7 low-pathogenic avian influenza virus in wild mallards in Poland provided by phylogenetic studies. Avian Pathol 40: 131-138.

Smietanka K, Minta Z, Wlodarczyk R, Wyrostek K, Jozwiak M, Olszewska M, Minias P, Kaczmarek K, Janiszewski T, Kleszcz A (2012) Avian influenza viruses in wild birds at the Jeziorsko reservoir in Poland in 2008-2010. Pol J Vet Sci 15: 323-328.

Spackman E, Senne DA, Myers TJ, Bulaga LL, Garber LP, Perdue ML, Lohman K, Daum LT, Suarez DL (2002) Development of a real-time reverse transcriptase PCR assay for type A influenza virus and the avian $\mathrm{H} 5$ and $\mathrm{H} 7$ hemagglutinin subtypes. J Clin Microbiol 40: $3256-3260$. 